\title{
BIDIMENSIONAL \& TRIDIMENSIONAL: TÉCNICAS DE DESENHO E SUAS CONTRIBUIÇÕES PARA O DESIGN
}

\author{
Frank Mendonça Costa \\ Faculdade FUCAPI \\ frank.costa13@gmail.com \\ Andressa Maria Cruz dos Santos \\ Faculdade FUCAPI \\ andressa.santos@fucapi.com
}

Resumo: Este trabalho visa apresentar quais as contribuições de uso das técnicas de desenho bi e tridimensionais - manuais ou digitais - para o design, com enfoque no processo criativo e projetual, nas habilidades específicas de quem os manuseia e no uso da ferramenta digital como complemento ou substituto do traçado à mão livre. A metodologia utilizada foi dividida em fases, onde a primeira buscou-se a fundamentação teórica da pesquisa com base nas pesquisas bibliográficas e documentais. A segunda foi a pesquisa exploratória e de campo realizada junto à acadêmicos finalistas e profissionais da área do design de Manaus através do instrumento Questionário elaborado no Google Forms para levantamento de dados. Os resultados obtidos mostram a pertinência de uso do desenho à mão livre nas etapas iniciais dos projetos convivendo em harmonia com os desenhos elaborados nos processos digitais. É enfatizado a necessidade da habilidade no domínio de uma das técnicas de representação na qual o designer deverá possuir na condução de seus projetos.

Palavras-chave: Desenho, Técnicas, Manual e Digital, Habilidades.

Abstratct: This work aims to present what the use of contributions of design techniques two-and three-dimensional - manual or digital - for the design, focusing on the creative and design process, the specific skills of those handling and the use of digital tool as a complement or substitute of tracing drawing freehand. The methodology was divided into phases, where the first sought the theoretical foundation of the research based on bibliographical and documentary research. The second was the exploratory and field research conducted with the finalists academic and professional Manaus design area through the elaborate questionnaire tool in Google Forms for data collection. The results show the relevance of using the freehand drawing in the early stages of projects coexisting in harmony with the designs developed in digital processes. It emphasized 
the need for skills in the field of one of the techniques of representation in which the designer must have in conducting their projects.

Keywords: Drawing, Techniques, Manual and Digital, Skills.

\section{INTRODUÇÃO}

Este artigo resulta de uma reflexão acerca do uso de técnicas de desenho bi e tridimensional no design - tanto no âmbito acadêmico quanto no profissional enquanto ferramenta do processo criativo e projetual. Para tanto, optou-se por analisar as contribuições de uso das técnicas de desenho bi e tridimensionais - manuais ou digitais - para o design, com enfoque no processo criativo e projetual, nas habilidades específicas que o acadêmico ou profissional de design possui e no uso da ferramenta digital como complemento ou substituto do traçado à mão livre.

No âmbito acadêmico, formulou-se um questionário com questões diretas, fechadas e abertas aplicado no universo de alunos e professores ${ }^{1}$ de design de Instituições de ensino privado e federal de Manaus. Quanto ao mercado de trabalho, tornou-se importante neste artigo fazer uma breve menção a profissão do designer, que envolve o talento inerente a cada indivíduo naquilo que pretende desempenhar como atividade profissional. Segundo um levantamento de estudo, intitulado Diagnostico do Design no Brasil, feito pelo Ministério do Desenvolvimento, Indústria e Comércio Exterior "o designer passa a ser compreendido como resultante do processo do debate que envolve principalmente o seu perfil profissional" (MDIC, 2014, p.87).

O estudo aponta que fatores como constantes transformações socioculturais e econômicas, bem como em virtude da aceleração científico tecnológica contribuem para a solidificação do designer no mercado, e baseando-se em dados do Internacional Council of Societies of Industrial Design (ICSID), o estudo do MDIC (2014) atesta que este perfil profissional do designer deve descobrir e avaliar relações estruturais, organizacionais, funcionais, expressivas e econômicas de seus projetos. O estudo aponta, também, sete atividades que são desempenhadas pelo profissional do design, independentemente da sua área de atuação, dentre as quais se destacam duas que são mais relevantes para esta investigação: "utilizar um procedimento metodológico para o desenvolvimento do trabalho" e "expressar ideias por meio de desenhos, imagens, textos, modelos, protótipos, etc". (MDIC, 2014, p.92).

Tais atividades vêm de encontro ao que é defendido por Straub et al (2004), principalmente no que se refere ao ato de expressar ideias por meio de desenho, que é o alvo investigativo deste trabalho acadêmico. $E$, um dos problemas fundamentais do desenho é como representar aspectos da realidade tridimensional em superfícies com apenas duas dimensões, visto que uma das premissas da função do desenho, com certeza, é de comunicar e desenvolver. Então como compreender a hierarquização, se é que existe uma, entre o bi e o tridimensional? O primeiro (bidimensional) foi

\footnotetext{
${ }^{1}$ Questionários enviados via internet para pessoas conhecidas e que exerciam alguma influência dentro das IES's (coordenadores de curso, professores e amigos) para divulgação e devida participação nesta pesquisa.
} 
superado em algum momento pelo segundo (tridimensional)? Como tais processos agregam conhecimento ao mundo do design?

O presente trabalho pretende mostrar quais as contribuições de uso das técnicas do desenho bi e tridimensional para o design, respondendo aos questionamentos acima suscitados principalmente no que tange ao uso dos recursos destas técnicas cujo imediatismo de resposta às necessidades ou deficiências projetuais a serem resolvidas exijam algum tipo de rascunho, gerando um conflito de uma ação no campo bidimensional para uma realidade que exige detalhes em três dimensões das representações gráficas.

\section{DESENVOLVIMENTO}

\subsection{Desenho e design}

Analisando o seu uso de uma forma intencional, o desenho nem sempre foi utilizado como uma técnica do processo criativo e sim como meio de comunicação, visto que nos registros da História da humanidade, nossos ancestrais primitivos já utilizavam desenhos como meio de representar cenas de hábitos e experiências de seu cotidiano no interior das paredes das cavernas usando as pinturas rupestres como forma de expressão e comunicação e seus dedos como utensílio no ato de desenhar. As culturas egípcias e gregas da antiguidade fizeram uso do desenho para ilustrar etapas de suas vidas em palácios, tumbas e templos sagrados, representando deuses e lendas de suas mitologias.

Um fato que muito acrescentou ao desenho, tanto nos utensílios quanto na técnica, foi a invenção do papel há mais de três mil anos pelos chineses, o qual influenciou todas as formas de desenho e surgiu para substituir couro, tecidos, pedras, folhas de palmeiras, blocos de barros ou argilas, ossos de baleias, bambu, papiro e outros materiais que foram usados com a mesma finalidade (PILLAR, 1996). Os chineses também inventaram a tinta nanquim, a acerca de 2000 a.C., mas foi no Japão entre os anos 1192 e 1600, época dos Samurais que se dedicavam às lutas e combates, e também às artes (desenhando natureza e cenas tradicionais da sua cultura), que o desenho teve seu aperfeiçoamento. A nanquim, muito utilizada hoje na técnica de croqui e na arte final, inicialmente era extraída de tinta preta liberada pelos moluscos marinhos da família dos octópodes (polvo e lula), hoje pode ser fabricada com pigmento negro extraído de compostos de carbono queimado (negro de fumo), uma variedade mais pura do carvão (SANTOS, 2015).

Apesar das invenções e representação de diversos cenários registrados até então, foi no Renascimento que o desenho ganhou estudos mais profundos e passou a explorar perspectiva, sombras, luz, proporções, cores e a anatomia humana para melhor retratar a realidade (FARIA, 2015). No Alto Renascimento foram aplicadas técnicas de representação como a vista em perspectiva dando ao objeto a impressão da tridimensionalidade, deixando-o com uma maior aparência realística, fidedigna ao original. Um dos artistas mais expressivos da arte renascentista foi Leonardo Da Vinci que entendeu que o desenho é fonte de conhecimento, segundo Tavares (2009) este era um tipo de processo intelectual que atende as ciências, possuindo a missão sublime de comunicar e desenvolver.

Da Vinci tratava o desenho como processo, um conceito antigo, porém contextualizado ao design, traduzido mais recentemente de forma conceitual por 
Miller (1988) como a atividade criativa, compreendida em oposição ao produto de uma criação de algo, ou alguma coisa. Pensamento compartilhado por Oliveira (2014, p.8), quando este, olhando para a nossa realidade amazônica, propõe uma nova prática no ensino de design no Amazonas, se contrapondo ao pensamento do que, até então, é modelo em voga, visto que "são processos de tradução, calcados em mera reprodução de modelos previamente estabelecidos". O autor traduz o sentimento de mudança no âmbito de ensino do design no Amazonas coletado dos discursos dos docentes da área, inconformados com as imitações das etapas do processo de criação dos modelos lá de fora.

A partir da Primeira Guerra Mundial o desenho passou a ser muito explorado nos periódicos em forma de caricatura e charges como uma verdadeira ferramenta da guerra civil tanto para criticar o oponente quanto para propagandas (FARIA, 2015). Hoje, apesar de ser muito estudado e praticado em suas mais diversas modalidades: técnico, artístico, charges, cartum, caricaturas, animes, mangás, grafite e outros, o desenho carrega a função de comunicar e colabora para o desenvolvimento da atual linguagem falada e escrita. E, é na função de comunicar que o desenho passa a ser definido junto com o design, e a origem de cada termo reforça o vínculo existente.

Gragnato (2008), com base na origem latina designare, afirma que a palavra design abrange tanto o sentido de designar quanto de desenhar, e drawing pode se referir, dependendo do uso, a um projeto (desígnio) ou simples ato do pensamento caracterizando o ato de desenhar. Em italiano, disegno, e em português desenho, "mantiveram o sentido mais amplo ligado não apenas ao fazer como também pensar". (MARTINS, 2007, p.2).

Wong (2010, p.41), ressalta que "o desenho enquanto criação visual deve ser muito mais que um mero embelezamento, deve ter um propósito". E, este processo quando exposto ao público, deve atender a uma mensagem predeterminada, além de suas exigências enquanto consumidores. Então pode-se supor que o desenho bem elaborado pode adquirir aspecto de uma expressão visual, portanto passa a ter também essência de design, de algo bem feito, de credibilidade e aceitação. Desta forma, Straub et al (2004, p.6) afirma ser "fundamental que cada designer tenha o domínio de um processo de representação que venha auxiliá-lo quando necessário criar, sabendo-se que o processo criativo é ligado ao ato de desenhar".

Neste contexto, nos recai o momento do insight que, pelo lampejo que é, quase um sopro, instantâneo, deve-se complementar com representações gráficas para externar as respostas encontradas naquele instante de inspiração para a resolução de um determinado problema ou dificuldade em curso, e é evidente que quanto mais fiel for a representação gráfica desta solução, maior e melhor será para todos a compreensão do estado do antes e, o do depois da intervenção projetada, ou seja, uma abordagem intelectual, e não intuitiva, da criação visual, que antecipa os problemas específicos a serem resolvidos (WONG, 2010).

\subsection{Especificidades das técnicas de representação}

O desenho bidimensional segundo Wong (2010, p.237), "possui aspectos de organização visual limitando o objeto numa área especifica sem profundidade, onde podem ser arrumadas marcas visíveis". Diferentemente da realidade tridimensional, que não é somente uma imagem plana, de comprimento e largura, mas sim um espaço com esta profundidade física denominado de terceira dimensão. Wong (2010), salienta 
também, que "o mundo bidimensional possui essências humanas caracterizado pelas atividades do desenho, da pintura, da impressão, do tingimento e, até mesmo, da escrita, onde a profundidade que se percebe neste ambiente é a do tipo ilusório". Esta afirmativa indica que na representação gráfica do objeto o resultado final pode ser abstrato ou figurativo, cabendo a percepção do olhar humano firmar o objetivo do bidimensional que é de estabelecer uma harmonia e ordem visual ou gerar interesses intencional.

No entanto a tridimensionalidade do objeto, que possui as mesmas atribuições do bidimensional, deve proporcionar uma alavancada na atitude do desenhista. Wong (2010, p.236), afirma que a definição de "um objeto tridimensional deve ter início e fim na mente do observador", de forma que se observado de diferentes ângulos e distâncias terá uma compreensão completa de sua realidade tridimensional. Portanto, na representação tridimensional é primordial que o designer seja capaz de manipular imaginariamente o objeto em estudo, girando-o em todas as direções e explorando as possibilidades da profundidade do espaço e a natureza dos diferentes materiais empregados afim de potencializar sua representação aos olhos do observador.

Segundo Straub et al (2004), uma imagem pode ser impactante, ser expressiva ou ser ignorada, dependendo do posicionamento do ângulo do observador, o que pode torná-la mais atraente e persuasiva. Se pensarmos na venda da ideia da solução projetada, torna-se fundamental a percepção do resultado alcançado de forma mais objetiva possível, e a tridimensionalidade potencializa isso. O convencimento está nos detalhes visualizados por parte do observador, e para isso, segundo os autores, usa-se a estratégia de "mostrar o maior número possível de faces do objeto empregando o uso de ângulo de visão diferenciado, o que pode atribuir efeitos de dramaticidade, movimento, dinamismo e plasticidade no momento de vender o produto final". (STRAUB et al, 2004, p.28).

Wong (2010) afirma que a linguagem visual constitui a base de criação do desenho. E é através deste procedimento que as representações serão interpretadas, configurando uma ligação visual de comunicação entre as pessoas. Não importa aqui qual dos dois processos serão empregados, manual ou digital, os elementos conceituais e visuais, como o ponto, a linha, o plano, o volume, a cor, a textura, estarão presentes coerentemente na composição final do desenho. E no que se refere aos elementos conceituais e visuais, Santaella e Nöth (1997, apud RUFCA, 2012, p.20), argumenta que "a representação imagética não se refere somente a uma imagem visual, mas traz uma relação complexa entre percepção desses elementos para o entendimento do projeto em design", relação esta que é o resultado de uma estrutura fisiológica fruto de registros armazenados no cérebro humano.

Para Tavares (2009), mesmo com a evolução dos meios digitais e de suas possibilidades mais elevadas para as soluções gráficas, os processos manuais ainda têm sua importância na manipulação e apresentação da primeira ideia no projeto. A autora corrobora com a tese de Straub et al (2004), de que há a possibilidade de plena convivência da tecnologia e da tradição, o que coloca o entendimento do desenho não somente como processo manual, mas também intelectual.

Segundo Wong (2010) a manualidade pode causar transtornos como perda de tempo e insatisfação dos resultados com técnicas meticulosas de acabamento. No entanto sabe-se que, o advento do computador possibilitou novos métodos para a criação do desenho abrindo novos horizontes para o design mostrando uma 
incompatibilidade avassaladora entre o material e o virtual. Esta intervenção, em suma, transfere ao designer uma maior liberdade para experimentar coisas novas e um maior controle sobre o que é criado. O que não está adequado no andamento do projeto pode ser alterado de imediato. As possibilidades de ações vão tornando-se mais amplas à medida que se vislumbra a evolução dos programas gráficos visuais.

\subsection{Design no Amazonas e as disciplinas que envolvem o desenho}

Segundo Bonfim (1997, p.28), "o conjunto de ciências empregadas na fundamentação do design caracteriza-o como atividade interdisciplinar". E a realidade do design no Amazonas corrobora com esta tese da interdisciplinaridade, visto que as Instituições de Ensino Superior (IES) que ministram o curso na capital, Manaus, elaboram seu ementário com disciplinas da matriz curricular que fazem uso de conceitos de ciências como a psicologia, matemática, história, etc., para desenvolvimento de suas atividades acadêmicas.

De fato, na academia deve-se manter o pensamento de que o design é uma atividade projetual que planeja a existência de algo no futuro, e que por si só não alcançaria os objetivos propostos nos projetos, carecendo, portanto, do complemento de conhecimentos de ciências limítrofes. Na IES Fucapi ${ }^{2}$ a própria disciplina de Desenho, do primeiro período, se utiliza dos conceitos de geometria, matemática a artes plásticas, tornando-se evidente o contato massificado do aluno com as práticas do desenho no desenvolvimento dos seus projetos.

No segundo período, as disciplinas de Criatividade e Prototipação/Modelagem exploram o uso de técnicas de desenho para o desenvolvimento de atividades que vão desde a definição do problema até o detalhamento do projeto final. Nelas, os alunos têm a liberdade em fazer uso da técnica que lhe é mais familiar para a representação das ideias iniciais, porém, há sempre a exigência do desenho técnico e, dependendo do tema da atividade proposta, explora-se um model sheet (digital) e story board (manual). Nos Trabalhos de Conclusão de Curso, temas relacionados ao desenho, técnicas de desenho ou de representação só são abordados quando o aluno possui, no mínimo afinidades, ou um profundo domínio do assunto.

E, quando surgem temas relacionados ao desenvolvimento de personagens para a sua devida construção, torna-se necessário o aluno demonstrar habilidades na aplicabilidade de uma técnica de desenho, manual ou digital, bidimensional ou tridimensional no processo criativo desta personagem. Estes dados são evidenciados pela quantidade de Trabalhos de Conclusão de Curso defendidos na área e por pessoas específicas, bem como experiência e observação própria do autor deste, como discente do curso de Design em análise.

Em Manaus há seis instituições de ensino superior que oferecem o curso de Design para a comunidade local. Destas, cinco são particulares, apenas uma é pública federal, ambas estão alinhadas com os segmentos de negócios envolvendo o mercado de design no Brasil apontado pelo estudo de Diagnóstico do Design Brasileiro (MDIC, 2014, p.69). As vertentes do design adotadas nestas instituições são: gráfico, produto, moda, digital e de interiores. Estas instituições, conforme seu ementário aplicam os conceitos de desenho e de suas respectivas técnicas em $80 \%$ das disciplinas ministradas em sua grade curricular.

\footnotetext{
${ }^{2}$ Fucapi, é a IES do autor.
} 


\subsection{Metodologia}

A metodologia utilizada neste artigo foi dividida em duas fases, onde a primeira buscou-se a fundamentação teórica da pesquisa com base nas pesquisas bibliográficas e documentais. A segunda foi a pesquisa exploratória e de campo através do instrumento Questionário (pesquisa telematizada - pesquisa em internet) para levantamento de dados, definindo-se como processo linear, onde primeiro ocorreu a definição do objetivo que é apresentar quais as contribuições de uso das técnicas de desenho bi e tridimensional - manuais ou digitais - para o design. Em seguida foi definida a estratégia de aplicação do questionário através da plataforma de formulários Google Forms. Para tanto, elaborou-se primeiramente as perguntas em um Brainstorming. Após adicionadas na plataforma de formulários, fez-se necessário realizar um pré-teste do questionário, visando a correção de pontos em duplicidade ou com difícil interpretação. Para finalizar, e após as devidas correções, o questionário foi devidamente preenchido e seus resultados foram apresentados através de gráficos para a maioria das questões.

\subsubsection{Pesquisa Bibliográfica}

Com a preocupação de se fazer entender sobre o tema explorado, buscou-se o embasamento teórico de autores e suas obras relativo as técnicas de representação manuais e digitais, nos campos conceituais do bidimensional e tridimensional através da pesquisa bibliográfica. Gil $(2002$, p.29) define a "pesquisa bibliográfica como aquela desenvolvida com base em material já elaborado, constituído principalmente de livros e artigos científicos". Desta forma uma pesquisa bibliográfica foi realizada em livros editados contidos no acervo da IES Fucapi, além de uma pesquisa online entre publicações em jornais e revistas eletrônicas, periódicos de congressos P\&D, analisando de forma crítica conteúdos literários de caráter científico pertinentes.

\subsubsection{Pesquisa Documental}

Foi realizada, também, uma pesquisa documental de caráter exploratório buscando familiaridade com o assunto estudado. Segundo Gil (2002), a pesquisa Documental é muito parecida com a Bibliográfica, se valendo de materiais que ainda não receberam um tratamento analítico, ou que ainda podem ser reelaborados de acordo com os objetivos da pesquisa. Sendo assim a pesquisa documental está constituída de um levantamento da matriz curricular (ementários) do curso de Design de instituições de ensino superior (IES) de Manaus afim de se fazer um comparativo do percentual de disciplinas que fazem uso, ou mencionam, em seus conteúdos os conceitos das técnicas de desenho, justificando o aprendizado e a relevância destas técnicas ministradas aos alunos do curso de design das referidas instituições.

\subsubsection{Sobre o Questionário}

O questionário, de perguntas abertas e fechadas, foi apresentado a comunidade acadêmica de design, da instituição de ensino superior IES Fucapi, onde participaram alunos finalistas e professores do corpo docente do curso, sendo estendida a profissionais graduados na área de design que atuam nas instituições de ensino superior de Manaus, como IES UFAM e IES UNINORTE, com titularidades profissional de graduação (Bacharel), Especialista, Mestre e Doutor. Os ementários são referentes aos cursos de design destas três instituições. 


\subsubsection{Análise do Questionário}

A análise do questionário foi realizada nos seguintes momentos: tabulação dos dados demográficos e, para questões abertas: a descrição. No momento descrição, registraram-se as respostas que merecem destaque, ou seja, aquelas que defendem com mais propriedade o uso de técnicas de desenho, sejam elas bi, ou tridimensionais, durante o processo criativo em projetos de design.

\section{CONCLUSÃO}

O questionário do Google Forms foi elaborado para que as respostas obtidas estivessem em texto corrido, de forma que o entrevistado ficasse à vontade com liberdade de expressar o seu sentimento a respeito do assunto (questão) explorado. Não foi, de maneira alguma, feita a distinção do grau de instrução com perguntas específicas para cada tipo de graduação, ou seja, todos tiveram acesso ao mesmo conjunto de questões e cada um respondeu conforme seu entendimento.

\subsection{Resultados}

Dos 50 questionários enviados, apenas 23 pessoas responderam em sua totalidade o que representa a amostra da pesquisa. Desses, 9 são alunos finalistas do curso de design e 14 são profissionais da área e, 100\% deles afirmaram ser relevante conhecer os fundamentos do desenho, principalmente para desenvolvimento de sketches (produtos, personagens, animações, identidades visuais, representação de ideias, orientação de projetos e conceitos).

O mesmo ponto de vista defendido por Straub et al (2004), justamente por ser o desenho a ferramenta mais dinâmica e imediata. Do total, 33,33\% afirma que teve contato na Academia com as duas técnicas, mas que hoje tem preferência pelas as que são em 2D, em desenho à mão livre, e que não descartam o uso eventual do 3D. Enquanto que $47 \%$ dos entrevistados afirma que seu estado de espirito sempre o influencia na escolha de uma técnica de representação; recaindo em $27,3 \%$, a situação de quem diz que nunca ou, às vezes, esta condição interfere no ato criativo.

Com relação ao uso de representação em $2 \mathrm{D}$ ou 3D no desenvolvimento de seus projetos, a maioria $(90,9 \%)$ dos entrevistados afirma que usa sim estes conceitos, e destes $(77,3 \%)$ entende que o desenho à mão livre se sobressai sobre os demais, e que ainda é essencial para a representação de ideias, visto que a rapidez com que é executada facilita na conservação da ideia pensada naquele momento. Faz parte do insight do designer, o que representaria uma extensão direta do pensamento criativo.

Todos os entrevistados mostraram-se concisos no entendimento do uso de determinada técnica de representação, e daquelas à mão livre, sobressaem-se o sketch, o rendering e o croqui, que na sua essência tomam como base o desenho, e como instrumento utilizado, o grafite (lápis), justificando ser de rápido execução e de fácil entendimento pelo cliente.

A grande maioria $(86,4 \%)$ concorda que a falta de um conhecimento mais técnico e aprofundado do desenho influencia na qualidade da representação de ideias, a preocupação de se fazer entender os conceitos gerados ante as necessidades do cliente vêm em primeiro lugar, daí a importância do feeling do designer para o domínio de determinada técnica. Quanto mais detalhes na representação, maior a aceitação pelo cliente da ideia vendida. 
Levando-se em consideração as três técnicas mais usadas pelos entrevistados (sketch, rendering, croqui) o grafite e a caneta esferográfica parecem ser os materiais da base das ideias representadas. Dependendo de qual delas (técnicas) será a escolhida outros materiais serão utilizados para o acabamento, como marcadores, hidrocor (bico chanfrado), corretivo líquido, pastel seco, caneta com tinta nanquim, lápis aquarelável, guache, giz de cera, carvão, além dos elementos de apoio como, esquadro, borracha, esfuminho e estilete, e, o da computação gráfica.

$100 \%$ dos entrevistados concorda que a harmonia entre os processos manuais e digitais é perfeitamente plausível entre um e outro, o que reforçaria a ideia de complementação de representação defendido por Straub et al (2004) e Tavares (2009), visto que na elaboração de alternativas, os conceitos são gerados em 2D (desenhos a mão livre), e melhorados com computação gráfica (3D). Para os mais experientes onde o uso destas ferramentas, como num brainstorming, após a concepção mental, numa preconcepção digital, com uso de croquis de concepção e explicativos, faz-se todo o sentido o start de conceitos potencializados, havendo ainda a opinião de que não há uma regra definida de uso das técnicas de representação, e sim prevalecerá o feeling do designer desempenhando sua habilidade na disponibilização de tempo e das características do projeto, conforme mostra o Quadro 1. 
Quadro 1 - Técnicas de representação à mão livre e digital praticadas por profissionais graduados em Design que atuam também como professores nas IES (Fucapi, UFAM e UNINORTE).

Fonte: "Elaborado pelo autor com base na pesquisa realizada".

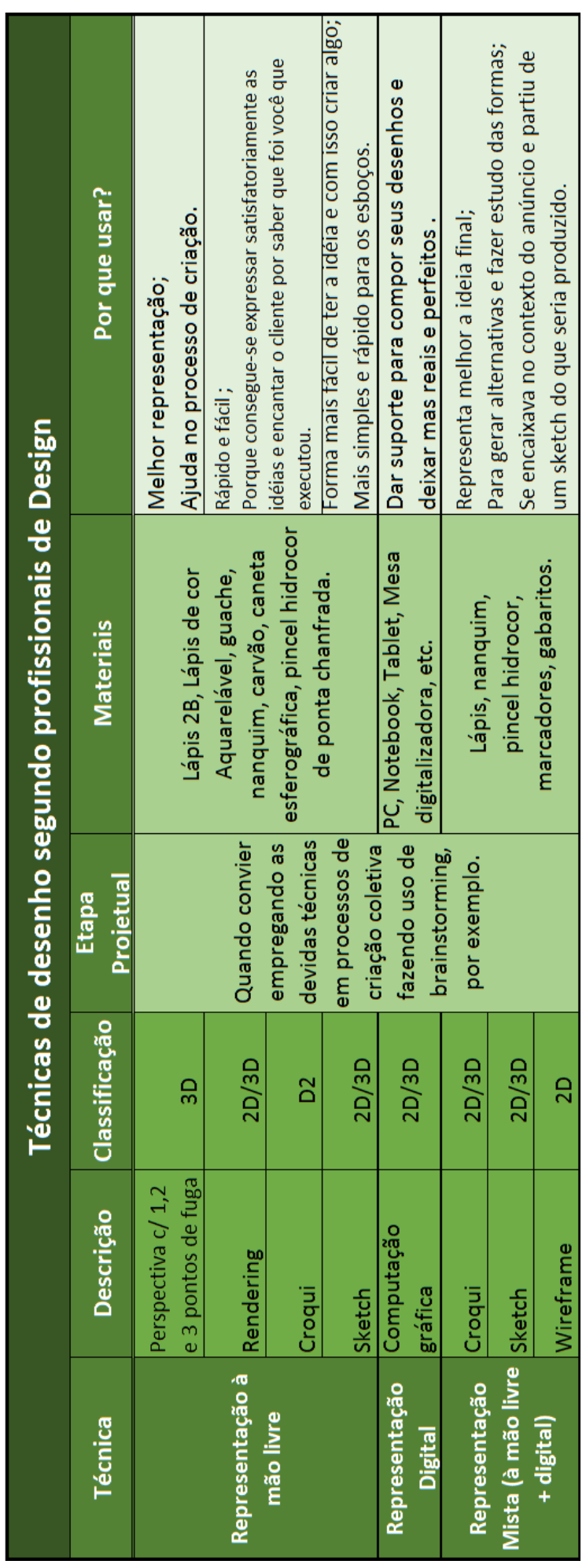

Não há um consenso entre os entrevistados concernente ao uso específico do 2D ou 3D nas etapas projetuais. No entanto percebe-se uma clara distinção de uso de tais ferramentas entre os mais experientes daqueles menos experiente em design. 
Quadro 2 - Técnicas de representação à mão livre e digital praticadas por alunos de Design nas IES (Fucapi, UFAM e UNINORTE).

Fonte: "Elaborado pelo autor com base na pesquisa realizada".

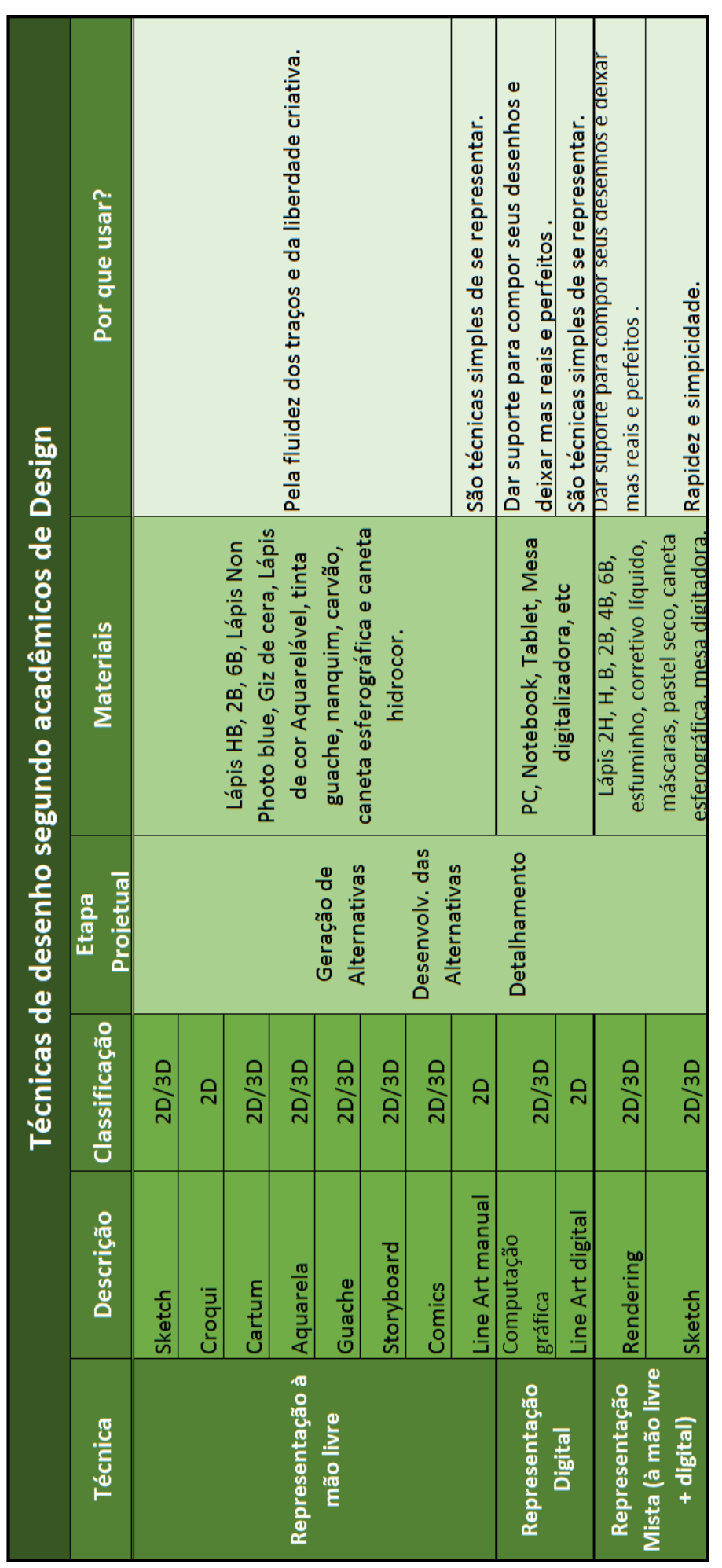

Para os que estão na academia as etapas de Geração de Alternativas, Desenvolvimento da Alternativa escolhida e Detalhamento das Especificações, são aquelas que serão aplicadas tais técnicas, conforme ilustrado no Quadro 2. 
Dentre os entrevistados, aqueles que deixaram de usar uma das técnicas $(12,5 \%)$ afirmaram que o motivo foi pela falta de habilidade em desenhar nem sequer uma simples reta, e isto no desenvolvimento projetual gera uma certa frustação. Enquanto que $100 \%$ dos entrevistados, mesmo aqueles que alegadamente não dominam nenhuma técnica de representação, são contundentes em afirmar que só se aprende desenhar, desenhando. É preciso treino e paciência, e nisso os mais experientes concordam, que somente o tempo irá apurar os traçados do desenho, pois estimular as ideias é um ótimo exercício de aprendizado.

\subsection{Considerações finais}

Podemos afirmar que uma imagem vale mais que mil palavras? $\mathrm{O}$ argumento aqui é muito forte e os resultados encontrados nas literaturas pesquisadas corroboram para a validação desta afirmativa onde se verifica que cada vez mais os designers estão buscando aprimoramento no domínio das técnicas de representação manual e digital. A subjetividade do desenho quando bem trabalhada resulta num produto bem elaborado, satisfazendo a todos os envolvidos. E esta subjetividade está contida nos toques das mãos do designer que deverá ter o domínio de um processo de criação visual aplicado nas etapas iniciais do projeto.

Este artigo tem a pretensão de apresentar quais as contribuições de uso das técnicas do desenho (bi e tridimensional) de aplicabilidade nos projetos de design visando facilitar a interpretação de conceitos das ideias desenvolvidas em cada etapa projetual. A pesquisa mostra que a grande maioria dos entrevistados usam os desenhos à mão livre, empregando técnicas como o sketch, o rendering e o croqui. As literaturas exploradas atestam estes procedimentos.

No tocante a hierarquização do desenho, Rufca (2012, p.27) mostra que o bidimensional precede o tridimensional, de forma que "nas etapas da construção da imagem que requerem inicialmente o esboço feito manualmente, este deve ser, na sequência, transportado e finalizado no meio digital, possibilitando o uso de técnicas computacionais", de forma que, em momentos distintos, o que for mostrado inicialmente ao cliente em desenhos volumétricos, deverá ganhar traços mais refinados tecnicamente para viabilizar o projeto.

Straub et al (2004, p.36) reforça este argumento ao salientar que "para se produzir um bom sketch com o auxílio de um software, é preciso que se tenha conhecimento prévio de técnicas mais comuns de desenho". Sua metodologia emprega o início do desenho feito à mão livre com caneta esferográfica para em seguida digitaliza-lo através de um scanner em alta resolução.

Vemos que mesmo depois de um grande avanço tecnológico dos meios digitais de representação visual iniciado no final do século passado com softwares modernos e máquinas de última geração, ainda temos uma necessidade enorme de usar os meios manuais para representar conceitos idealizados em nosso íntimo. Os mais entusiastas à época diziam que o bidimensional estava fadado ao desuso, no entanto não é a realidade do momento. A pesquisa mostra que os conceitos de bi e tridimensional podem conviver em harmonia desde que se tenha o bom senso de saber em que momento pode-se aplicar um ou outro processo nas etapas projetuais de design.

É neste momento que o designer precisa demonstrar seu feeling, sua intuição. E, isto está claramente evidente nos depoimentos de profissionais do design local, coletado no questionário do Google Forms, e de relato nas obras de Straub et al 
(2004), Tavares (2009) e Wong (2010), onde defendem que carecemos do imediatismo de recursos visuais para vendermos nossas criações, mas, sem as ambiguidades inerentes a falta de habilidade ou despreparo técnico nos traçados do desenho.

A manualidade empregada nas representações visuais de projetos de design traduz um sentimento de poesia na percepção simbólica do que deverá representar a alma do produto. Este conceito parece ser o que as empresas estão procurando para alavancar seus empreendimentos, com valores e crenças que deem credibilidade aos produtos de criação do design. Já os conceitos de bi e tridimensional se confundem no uso dos recursos manuais e digitais, pois ambos procuram os efeitos da terceira dimensão em uma composição, como o emprego da perspectiva, jogo de luz e sombra, e o posicionamento angular do objeto como sustentação de uma imagem ilusória tridimensional que ajudam na venda da ideia possibilitando ao observador compreender melhor o conceito do produto idealizado.

De tudo o que foi mostrado até o momento, percebe-se que o mercado é exigente, conforme identificado no estudo do MDIC (2014), e o designer como agente catalizador dos conflitos de produtos e consumidores precisa ter responsabilidade no desenvolvimento de seus projetos. Precisa, também, desenvolver um raciocínio sistemático de modo a estabelecer uma harmonia entre interesses e a beleza no resultado final do projeto. $E$, isto pode ser alcançado através do domínio dos processos de representação do seu interior, traduzindo para o mundo exterior, como em momentos de insights, a sua competência enquanto profissional do ramo.

A presente pesquisa demonstra uma gama de possibilidades de caminhos que envolve o despertar do designer para o mundo bidimensional e tridimensional das técnicas de representação do desenho, pois é destes artifícios que os projetos de design se fundamentam. De fato, percebe-se que o não domínio de técnicas de representação gera conflitos para os estudantes na época da academia, especialmente para aqueles que ainda estão começando a ter os primeiros contatos com o mundo do design, e experimentando conceitos novos como os dos desenhos bi e tridimensional, com reflexos negativos futuros no âmbito profissional se não forem trabalhados adequadamente, e isto carece de atenção e de estudos mais aprofundados.

\section{REFERÊNCIAS}

BONFIM, Gustavo Amarante. Fundamentos de uma Teoria Transdisciplinar do Design: morfologia dos objetos de uso e sistemas de comunicação. / Universidade Federal de Pernambuco - Departamento de Design. ESTUDOS EM DESIGN V.V, n.2 (dez), 1997. Rio de Janeiro: Associação de Ensino de design do Brasil, Revista de periodicidade semestral.

FARIA, Caroline. História do desenho. São Paulo, 2015. Disponível em: < www.infoescola.com/artes/história-do-desenho/. Acesso em: 01 nov. 2015.

GIL, Antônio Carlos. Como elaborar projetos de pesquisa. 4.ed. São Paulo; Atlas, 2002.

GRAGNATO, Luciana. 0 desenho no design de moda. 2008. 86 f. Dissertação (Mestrado) - Universidade Anhembi Morumbi, São Paulo, 2008. Disponível em: <http://www.anhembi.br/mestradodesign/pdfs/luciana.pdf>. Acesso em: 02 nov. 2015. 
MARTINS, Luiz Geraldo Ferrari. A etimologia da palavra desenho (e design) na sua língua de origem e em quatro de seus provincianismos: desenho como forma de pensamento e de conhecimento. São Paulo, 2007. Disponível em:

<http://www.mackenzie.br/fileadmin/Graduacao/FAU/Publicacoes/PDF_IIIForum_a/M ACK_III_FORUM_LUIZ_MARTINS_2.pdf> Acesso em: 01 nov. 2015.

MILLER, Willian Richard. A Definição do Design. 1988. Disponível em:

<http://www.feiramoderna.net/ufes/projeto1/MILLER-A-definicao-de-Design.pdf> Acesso em: 26 ago. 2015.

MINISTÉRIO DO DESENVOLVIMENTO, INDÚSTRIA E COMÉRCIO EXTERIOR (MDIC). Diagnostico do Design Brasileiro. Brasília, 2014. Disponível em:

<http://www.mdic.gov.br/arquivos/dwnl_1415903068.pdf> Acesso em: 26 ago. 2015.

OLIVEIRA, Alexandre Santos. 0 ensino do design no Amazonas: discursos sobre identidade cultural. 11요 Design. 2014. Disponível em:

$<$ http://www.proceedings.blucher.com.br/article-details/o-ensino-do-design-noamazonas-discursos-sobre-identidade-cultural-12768> Acesso em: 02 dez. 2015.

PILLAR, Analice Dutra. Desenho \& escrita como sistema de representação. Porto Alegre: Artes Médicas, 1996.

RUFCA, Sidney. Design de produto: técnicas e tecnologias de representação visual. Tese de mestrado, 2012. Disponível em:

<http://www.sitios.anhembi.br/tedesimplificado/handle/TEDE/1609> Acesso em: 27 ago. 2015.

SANTOS, Richardson. Sobre a tinta nanquim. Belo Horizonte, 2015. Disponível em < https://estudionanquim.wordpress.com/sobre-a-tinta-nanquim/> Acesso em 03 set. 2015.

STRAUB, Ericson, et al. ABC do rendering. Curitiba, PR: Infolio Editorial, 2004.

TAVARES, Paula. $\mathbf{O}$ desenho como ferramenta universal. $\mathbf{O}$ Contributo do processo do desenho na metodologia projetual. Diseño en Palermo. Encuentro Latinoamericano de Diseño, 2009. Disponível em:

<http://fido.palermo.edu/servicios_dyc/encuentro2007/02_auspicios_publicaciones/a ctas_diseno/articulos_pdf/ADC072.pdf> Acesso em: 02 set. 2015.

WONG, Wucius. Princípios de Forma e Desenho / Wucius Wong; [tradução Alvamar Helena Lamparelli]. - 2a Ed. - São Paulo: Editora WMF. Martins Fontes, 2010. 